\title{
Modeling population viability of local proboscis monkey Nasalis larvatus populations: conservation implications
}

\author{
D. J. Stark ${ }^{1, *}$, V. Nijman ${ }^{1}$, S. Lhota ${ }^{2,3}$, J. G. Robins ${ }^{1}$, B. Goossens ${ }^{4,5}$ \\ ${ }^{1}$ Oxford Brookes University, School of Social Sciences and Law, Oxford OX3 0BP, UK \\ ${ }^{2}$ Department of Zoology, Faculty of Science, University of South Bohemia, Branišovská 31, 37005 České Budějovice, \\ Czech Republic \\ ${ }^{3}$ Ústí nad Labem Zoo, Drážd'anská 23, 40007 Ústí nad Labem Zoo, Czech Republic \\ ${ }^{4}$ Cardiff School of Biosciences, Cardiff University, Biomedical Sciences Building, Museum Avenue, Cardiff CF10 3AX, UK \\ ${ }^{5}$ Danau Girang Field Centre, c/o Sabah Wildlife Department, Wisma Muis, 88100 Kota Kinabalu, Sabah, Malaysia
}

\begin{abstract}
Population viability analysis (PVA) is a predictive procedure that uses different modeling approaches to estimate species vulnerability to extinction. Using the stochastic modeling software VORTEX, we assessed the status of proboscis monkeys Nasalis larvatus in 3 fully or partially protected areas in Borneo, 1 in the Malaysian state of Sabah and 2 in the Indonesian provinces of Kalimantan. Species-specific life-history parameters were used when possible, and missing parameters were taken from other populations or species. We tested the sensitivity of final predicted population size to $20 \%$ variation around the possibly inaccurate parameter estimates. The model we used predicts that in the absence of any management, the Malaysian population will remain fairly stable, whilst the 2 Indonesian populations will decrease by more than half, the smallest going effectively extinct in $30 \mathrm{yr}$. We investigated whether management strategies, such as reforestation, corridors to reconnect sub-populations, harvesting, reduction of deforestation and controlling fires, might help forestall population extirpation at each site. Fire had the greatest impact on the Indonesian populations, although hunting is also likely to play an important role. Remedial action to reduce the frequency and extent of fires, perhaps by regulated land clearing for agriculture, should slow proboscis monkey population decline and provide more time to collect the data necessary to evaluate other management decisions. As information regarding mortality, the effect of fire, and hunting rates on proboscis monkeys is limited, further research should concentrate on these areas to improve PVAs for this species.
\end{abstract}

KEY WORDS: Population modeling - VORTEX • Extinction • Deforestation • Borneo · Kinabatangan $\cdot$ Kalimantan

\section{INTRODUCTION}

Population viability analysis (PVA) is a predictive tool that estimates species vulnerability by calculating the probability of population extinction (Miller \& Lacy 2005). By altering demographic and environmental variables, researchers can use PVA models to compare management actions and prioritize research needed for target populations (Hamilton \& Moller 1995). Although PVA models are not intended to determine the absolute risk of extinction over long periods of time, they are effective as tools to support policy decisions on habitat management and conservation planning over short time frames (Shaffer et al. 2002). PVA models can help direct funding to priority populations where it can be used most efficiently, an 
important aspect for conservation planning when funding is sparse.

Proboscis monkeys Nasalis larvatus occur throughout the island of Borneo, which comprises the Malaysian states of Sabah and Sarawak, the Sultanate of Brunei and the Indonesian provinces of East, South, Central and West Kalimantan. Proboscis monkeys are mainly confined to peat and freshwater swamp forests, mangrove forests and lowland riverine forests. Whilst fire, hunting and illegal wildlife trade threaten the survival of many proboscis monkey populations, the overarching threat to their population is believed to be habitat loss (Salter \& MacKenzie 1985, Meijaard \& Nijman 2000). Through logging and forest conversion to agriculture, proboscis monkey habitat is the most threatened habitat type in Borneo (Meijaard \& Nijman 2000), as landcover is decreasing at alarming rates, particularly in mangrove forests (Langner et al. 2007).

Protected areas in Borneo are becoming increasingly isolated, and buffer zones are degrading (Curran et al. 2004). In Sabah, only $15 \%$ of proboscis monkey groups are in fully protected areas. The remaining populations are divided almost equally between living completely outside of the reserve network or within sustainably managed permanent forest timber reserves (Sha et al. 2008). Similarly, the majority of the orang-utan Pongo pygmaeus populations in Sabah live in non-protected areas (Ancrenaz et al. 2005). Yeager \& Blondal (1992) estimated that in Kalimantan 5000 proboscis monkeys live in protected areas. However, as there is no difference in deforestation rates between protected and non-protected areas in Kalimantan, living in protected areas does not guarantee protection for proboscis monkeys (Curran et al. 2004). Protected lowland forests in Kalimantan decreased by 56\% from 1985 to 2001, and, by 2001 , > $50 \%$ of the remaining protected lowland forests in Kalimantan overlapped with concessions and plantations (Curran et al. 2004). Areas set aside for protection are being distributed for timber concessions and plantations, mining is poisoning the rivers, and the forests are being cleared for agriculture (Meijaard \& Nijman 2000, Curran et al. 2004, S. Lhota unpubl. data). By carrying out PVA for populations in well-studied protected areas, the findings can be used to ameliorate the situation for other populations before they are extirpated.

A previous PVA for proboscis monkeys by Manansang et al. (2005) used the software VORTEX. This model does not include sensitivity testing to examine how variation in parameter estimates can affect the final population size. We used recent survey data from 3 well-studied proboscis monkey populations, together with sensitivity testing, to examine the viability of these populations. Ultimately, the goal of the present study was to improve on existing PVAs and examine management actions that might be extrapolated to populations throughout Borneo. As conditions differ by location, performing smaller scale PVA models can provide more useful and catered results than an island-wide model. Running models for wildlife sanctuaries, forest reserves, or national parks can assist the authorities in the direction needed to improve species and site management.

\section{METHODS}

\section{Study species}

Proboscis monkeys Nasalis larvatus live in either stable 1-male groups or all-male groups (Bennett \& Sebastian 1988, Yeager 1990, Boonratana 2000). A number of groups may occasionally travel together and sleep in close proximity at night, forming a second level of social organization called a band (Bennett \& Sebastian 1988, Yeager 1991, Boonratana 1993, Sebastian 2000). Groups rarely travel more than half a day's journey from the river-typically not more than $2 \mathrm{~km}$ (Sebastian 2000), because they return to the riverside most nights. Both males and females disperse (Bennett \& Sebastian 1988). Among females, sub-adult female dispersal is more common, although dispersal of adult females with infants has been observed as well (Matsuda et al. 2009).

Proboscis monkeys are protected by law throughout their range, and are included in Appendix 1 of the Convention on International Trade in Endangered Species of Wild Fauna and Flora, precluding all international commercial trade. The species is listed as Endangered (A2bc) on the IUCN Red List (Meijaard et al. 2008), with a declining population trend.

\section{Study sites}

Our study sites included 3 of the largest proboscis monkey populations in Borneo, where the monkeys live in and around protected areas: the Lower Kinabatangan Wildlife Sanctuary, Balikpapan Bay, and Danau Sentarum National Park (Fig. 1).

The Lower Kinabatangan Wildlife Sanctuary (LKWS; $5^{\circ} 10^{\prime}$ to $5^{\circ} 50^{\prime} \mathrm{N}, 117^{\circ} 40^{\prime}$ to $118^{\circ} 30^{\prime} \mathrm{E}$ ) is located along the Kinabatangan River in the Malay- 


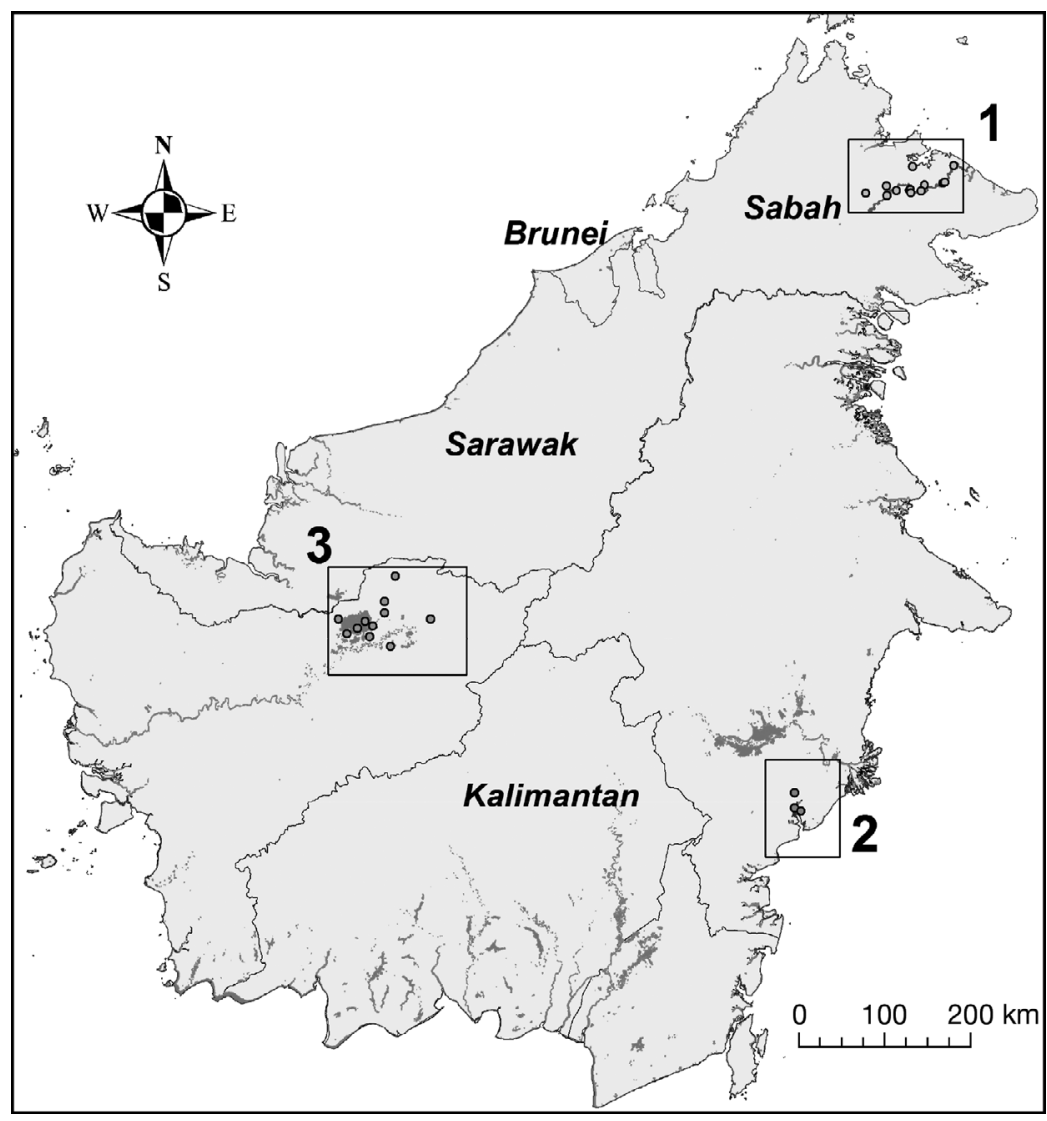

Fig. 1. Location of study sites in Borneo: (1) Lower Kinabatangan Wildlife Sanctuary, Sabah, Malaysia ( $5^{\circ} 10^{\prime}$ to $5^{\circ} 50^{\prime} \mathrm{N}, 117^{\circ} 40^{\prime}$ to $\left.118^{\circ} 30^{\prime} \mathrm{E}\right)$; (2) Balikpapan Bay, East Kalimantan, Indonesia $\left(1^{\circ} 8^{\prime} \mathrm{S}, 116^{\circ} 45^{\prime} \mathrm{E}\right)$; and (3) Danau

Sentarum National Park, West Kalimantan, Indonesia $\left(0^{\circ} 51^{\prime} \mathrm{N}, 112^{\circ} 6^{\prime} \mathrm{E}\right)$

tions, respectively. As the LKWS consists of different habitat types along the river, the overall value for change in forest cover by Langner et al. (2007) for all habitat types is used $(-1.7 \%)$. Hunting is considered minimal, and fires are generally absent (Boonratana 1993, B. Goossens unpubl. data).

Balikpapan Bay is located on the coast of East Kalimantan, Indonesia $\left(1^{\circ} 8^{\prime} \mathrm{S}, 116^{\circ} 45^{\prime} \mathrm{E}\right)$. Within Balikpapan Bay is the Sungai Wain Protection Forest, a $100 \mathrm{~km}^{2}$ nationally recognized protected area, designated as such in the 1940s for watershed protection and not necessarily wildlife conservation (Fredriksson \& de Kam 1999). Balikpapan Bay is surrounded by $170 \mathrm{~km}^{2}$ of coastal mangrove forest, which, together with an immediately adjoining fringe of nonmangrove forest, provides suitable habitat for proboscis monkeys (S. Lhota unpubl. data). Only 1 to $2 \%$ of the estimated 1400 proboscis monkeys live within the protected area (S. Lhota unpubl. data). Population size was estimated through surveys conducted in 2007/2008. Although the population is considered to be divided into 3 sub-populations (of

sian state of Sabah. The Kinabatangan River is the longest river in Sabah, flowing from the east coast, reaching $560 \mathrm{~km}$ inland and with a catchment area of $16800 \mathrm{~km}^{2}$. Designated a wildlife sanctuary in 2005, the LKWS consists of 10 forest blocks (referred to as lots) totalling $270 \mathrm{~km}^{2}$ (Goossens et al. 2005), comprised of seasonal and tidal swamp forests, permanent freshwater swamps, mangrove forest and lowland dipterocarp forests (Davison 2006). Initial proboscis monkey population sizes for this model are based on surveys we conducted in 2003 and 2009. Extracting from an additional river survey by Sha et al. (2008), we defined 3 sub-populations isolated as a result of habitat fragmentation caused mainly by villages and oil palm plantations, and assumed no dispersal occurred between these sub-populations. The size of each sub-population was based on the approximate percentage of overall group distribution (Sha et al. 2008): 35, 60 and $5 \%$ of the total estimated population size of 3000, from the eastern/coastal region, the mid- and the furthest inland sub-popula-
200, 1130 and 70 individuals) separated by unsuitable habitat for groups, proboscis monkeys have been occasionally reported moving through such places, and the sub-populations are, therefore, not effectively genetically isolated. Due to the lack of data on dispersal rates, the sub-populations are considered continuous in our model. Land-cover loss in mangroves was estimated by Langner et al. (2007) to be almost $8 \% \mathrm{yr}^{-1}$. However, this conversion rate is based on the years of shrimp farming conversion, which has now slowed down substantially, particularly in Balikpapan Bay. While halving the estimated values from Langner et al. (2007) to $4 \%$ may still be an over-estimate, it is nonetheless retained here due to the current land conversion for industrial and urban use. In addition, the proposed Pulau Balang Bridge will effectively split the mangrove from the non-mangrove forest and open up uncontrollable access to the area, particularly in the Sungai Wain Protection Forest. Hunting is considered negligible in Balikpapan Bay. 
Danau Sentarum National Park (DSNP) is located in West Kalimantan, Indonesia $\left(0^{\circ} 51^{\prime} \mathrm{N}, 112^{\circ} 6^{\prime} \mathrm{E}\right)$, with its northern boundary $\sim 20 \mathrm{~km}$ south from the Sarawak border. As part of the upper Kapuas River floodplain, DSNP is a network of connecting lakes, rivers, freshwater swamps and peat swamp forests, with swamps comprising almost half of the park area (Giesen \& Aglionby 2000). DSNP was initially designated as a wildlife reserve in 1982 but by 1994 had increased its original boundary of $80 \mathrm{~km}^{2}$ to $132 \mathrm{~km}^{2}$ (Giesen \& Aglionby 2000, Sebastian 2000). Although the park was upgraded from a wildlife reserve to a national park in 1999 (Giesen \& Aglionby 2000), there are still no clear borders, and it remains effectively a 'paper park' (Wadley 2006). Population numbers were obtained by surveys carried out by Sebastian (1994) and Robins (2008). Due to fragmentation and high river traffic, the population was considered to be broken into 5 isolated sub-populations, with no dispersal between them (Robins 2008). As the area is mostly peat swamp forest and there are a number of villages in and around DSNP, we set the loss in forest availability to $2.24 \%$, based on changes in peat swamp coverage throughout Borneo (Langner et al. 2007). Hunting of proboscis monkeys occurs in DSNP (Meijaard \& Nijman 2000, Robins 2008). As proboscis monkeys are protected by law, obtaining information on hunting has been difficult. However, preliminary data from DNSP suggests village groups tend to hunt once a month, with an estimated success rate of $60 \%$ (J. G. Robins unpubl. data). Therefore, assuming 1 hunting group goes out once a month, approximately 7 proboscis monkeys are hunted in a year per area. Of the 2 ethnic groups interviewed regarding hunting proboscis monkeys at DSNP, Iban only hunt adult males, whereas Mayan target all ages and sexes (Robins 2008). The total number hunted is divided by the number of age/sex classes, giving a total of 2 preadult females, 3 pre-adult males, 1 adult male and 1 adult female. These figures are underestimates as it is unlikely that only hunters from 1 village are hunting concurrently.

\section{Software}

PVA simulations were run using the software VORTEX V. 9.99b (Lacy et al. 2009), chosen because it is appropriate for the life-history parameters of proboscis monkeys (Miller \& Lacy 2005). Results recorded after each simulation were: the probability of extinction (PE), mean time to extinction (TE), deterministic growth rate (det-r), mean stochastic growth rate (stoc-r) and mean number of individuals for surviving populations (N-extant). 'Deterministic $r$ ' is the projected growth rate of the population, which does not include stochastic events. If stoc-r is close to det-r, then the population is considered stable. If stoc-r is less than det-r, then the population is subject to fluctuations. Variation across simulated populations is reported as a standard deviation, and, when this number is half or more than $\mathrm{N}$, the population is unstable or more susceptible to fluctuations (Ballou et al. 2003).

\section{Baseline scenarios}

An extensive literature review on proboscis monkey group compositions and life-history traits was used to develop the parameters for the baseline scenarios (Tables $1 \& 2$ ). We set simulations to run 2000 times representing $50 \mathrm{yr}$, a period chosen to represent a functional management time frame. Extinction was defined as 1 sex remaining. As there are no data on inbreeding depression for proboscis monkeys, we used the generalized value calculated for mammals (Ralls et al. 1988) and set it as due to lethal alleles only. Due to the small geographical area occupied by each population, we assumed that environmental factors have an equal influence on all sub-populations within the area. We defined the following parameters as those that can be influenced by land management practices: fires, hunting, and habitat reduction, which is assessed by a change in carrying capacity (Table 2).

Calculated species-specific parameters were sex ratio at birth, proportion of breeding females, and mate monopolization. Estimates for the parameters were calculated from detailed studies of group composition. As it is thought that the group composition of proboscis monkeys varies in different habitat types, these parameters were calculated using values recorded in a similar habitat type, except for sex ratios at birth, due to limited studies distinguishing between male and female infants. The proportion of females breeding was calculated by dividing the total number of infants by the total number of adult females. To calculate the annual mean number of successful mates for a male, the number of infants per year was divided by the number of males, i.e. this is a polygynous breeding system. Since the interbirth interval of proboscis monkeys is approximately $2 \mathrm{yr}$, and most studies categorized infants as from 0 to $2 \mathrm{yr}$, the total number of infants was divided by 2 to obtain the number of infants per year. 
Table 1. Species-specific parameters. Input values and rationale for values used in VORTEX simulations. EV: environmental variance; SD: standard deviation; PVA: population viability analysis; source of data - 1: Boonratana (1993); 2: Boonratana (2000); 3: R. Lacy (pers. comm.); 4: Miller \& Lacy (2005); 5: Manansang et al. (2005); 6: Murai (2004); 7: Ralls et al. (1988); 8: Yeager \& Boonratana (in press) ; na: not applicable; -: no source

\begin{tabular}{|c|c|c|c|}
\hline Species-specific input parameters & Value & Rationale & Source \\
\hline Inbreeding depression $^{\mathrm{a}}$ & 3.14 & $\begin{array}{l}\text { Generalized value for mammals; detrimental } \\
\text { alleles not considered; } 100 \% \text { of inbreeding depression } \\
\text { is due to recessive lethal alleles }\end{array}$ & 3,7 \\
\hline $\begin{array}{l}\text { Reproduction and survival } \\
\text { environmental concordance }\end{array}$ & Yes & Good survival year means good year for reproduction & - \\
\hline Correlation among populations in EV & 1 & $\begin{array}{l}\text { Sub-populations at each site are considered } \\
\text { synchronized in reproduction and survival }\end{array}$ & - \\
\hline Dispersal age range/survival rate & na & $\begin{array}{l}\text { Sub-populations are defined as isolated; no dispersal } \\
\text { possible }\end{array}$ & - \\
\hline Breeding system & $\begin{array}{l}\text { Long-term } \\
\text { polygamy }\end{array}$ & $\begin{array}{l}\text { Demographically does not differ if pairing is long-term } \\
\text { or not }\end{array}$ & 4,8 \\
\hline $\begin{array}{l}\text { Age of first reproduction (yr) for: } \\
\text { females/males }{ }^{\mathrm{a}}\end{array}$ & $5 / 7$ & $\begin{array}{l}\text { Estimated for females and males to be } 3-5 \text { and } 5-7 \mathrm{yr} \text {, } \\
\text { respectively }\end{array}$ & 6 \\
\hline Max. age of first reproduction $(\mathrm{yr})^{\mathrm{a}}$ & 25 & Assumed to be able to reproduce their entire adult life & 6 \\
\hline Number of broods per year & 1 & Inter-birth interval up to $24 \mathrm{mo}$, gestation ca. $166-200 \mathrm{~d}$ & 6,8 \\
\hline Number of progeny per brood & 1 & Twins regarded as rare/insignificant & 8 \\
\hline Sex ratio at birth $(\% \text { males })^{a}$ & 41.7 & $\begin{array}{l}\text { Calculated using data differentiating infant sex in } \\
\text { all habitat types }\end{array}$ & 1,2 \\
\hline Density-dependent reproduction & No & Reproduction not reduced when resources are limited & - \\
\hline Distribution of broods/year (\%) & $1: 100$ & - & - \\
\hline $\begin{array}{l}\text { Distribution of offspring/female/brood } \\
\text { Mortality rates }^{\mathbf{a}}\end{array}$ & Specify exact & - & - \\
\hline $\begin{array}{l}\text { Females/males, age } 0-1 \text { yr }(\%) \\
(\text { SD due to } E V=8)\end{array}$ & 40 & Same mortality rates used for males and females for all & 5 \\
\hline $\begin{array}{l}\text { Females/males, age } 1-2 \text { yr ( } \%) \\
(\text { SD due to } \mathrm{EV}=2)\end{array}$ & 10 & $\begin{array}{l}\text { models, using values from previous PVA, which are cal- } \\
\text { culated based on primates of similar size or life history }\end{array}$ & 5 \\
\hline $\begin{array}{l}\text { Females/males, adults }(\%) \\
(\mathrm{SD} \text { due to } \mathrm{EV}=1)\end{array}$ & 5 & & 5 \\
\hline $\begin{array}{l}\text { Females/males, adults }(\%) \\
(\mathrm{SD} \text { due to } \mathrm{EV}=3.5)\end{array}$ & $\begin{array}{l}-10.9+[(2)(\text { Age })] \\
+[(0.04)(\text { Age } 2)]\end{array}$ & As age increases, percent mortality increases & 5 \\
\hline
\end{tabular}

We define a population as the combination of all sub-populations at a particular site. Sub-populations are considered to be isolated from each other, except at Balikpapan Bay.

\section{Sensitivity testing}

Sensitivity testing (ST) was carried out to ensure the quality of data, particularly for parameters using data from other primate species with similar life histories (i.e. inbreeding depression, mortality rates) or estimated values from previous studies (i.e. severity of catastrophes, maximum age of reproduction). We used ST to identify parameters showing the strongest influence on population trends, i.e. those that should be further investigated to improve the modeling accuracy for this species. As there are relatively more studies on proboscis monkeys in the LKWS, we conducted ST using the baseline model from this area, but only for the applicable variables (Table 3). Models were run 100 times representing a $50 \mathrm{yr}$ period simultaneously for all sub-populations at each site. We examined the sensitivity of the following parameters by varying their estimate within $\pm 20 \%$ of the baseline value: inbreeding, percent of males at birth, 
Table 2. Site-specific parameters. Input values and rationale for values used in VORTEX simulations. LKWS: Lower Kinabatangan Wildlife Sanctuary, Sabah, Malaysia; BB: Balikpapan Bay, East Kalimantan, Indonesia; DSNP: Danau Sentarum National Park, West Kalimantan, Indonesia; EV: environmental variance; SD: standard deviation; source of data - 1: Bennett \& Sebastian (1988); 2: Boonratana (1993); 3: Boonratana (2000); 4: Dennis (1999); 5: Dennis et al. (2000); 6: Dennis et al. (2005); 7: R. C. Lacy (pers. comm.); 8: Langner et al. (2007); 9: S. Lhota et al. (unpubl. data); 10: S. Lhota (unpubl. data); 11: Manansang et al. (2005); 12: Matsuda (2008); 13: Robins (2008); 14: Sebastian (1994); 15: Sha et al. (2008); 16: Yeager (1990); na: not applicable

\begin{tabular}{|c|c|c|c|c|c|}
\hline Input parameter & LKWS & BB & DSNP & Rationale/explanation & Source \\
\hline $\begin{array}{l}\text { Number of sub- } \\
\text { populations }{ }^{\mathrm{a}}\end{array}$ & 3 & 1 & 5 & $\begin{array}{l}\text { Isolation due to forest fragmentation and villages } \\
\text { (and high river traffic in DSNP) }\end{array}$ & $9,13,14,15$ \\
\hline $\begin{array}{l}\text { Catastrophes } \\
\text { (risk, \%) }\end{array}$ & na & $\begin{array}{l}\text { Fire } \\
(20)\end{array}$ & $\begin{array}{l}\text { Fire } \\
(20)\end{array}$ & $\begin{array}{l}\text { Fires used for shifting cultivation and clearing plantations, } \\
\text { large fires occur approximately once every } 5 \mathrm{yr}\end{array}$ & $4,5,6,8$ \\
\hline $\begin{array}{l}\text { Catastrophe severity: } \\
\text { reproduction/survival }{ }^{\text {a }}\end{array}$ & na & $\begin{array}{l}0.5 / \\
0.77\end{array}$ & $\begin{array}{l}0.5 / \\
0.77\end{array}$ & $0 \%$ decrease in breeding and $23 \%$ increase in mortality & 11 \\
\hline $\begin{array}{l}\text { Proportion of females } \\
\text { breeding }(\%)(E V=7 \%)^{\mathrm{a}}\end{array}$ & 45.8 & 58.6 & 64.1 & $\begin{array}{l}\text { Inter-birth interval up to } 24 \mathrm{mo} \text {; studies with detailed } \\
\text { group composition for all habitat types } \\
\text { (calculated as no. of infants/total no. of adult females) }\end{array}$ & $1,2,3,12,16$ \\
\hline $\begin{array}{l}\text { Mate monopolization } \\
(\% \text { breeding males })^{\mathrm{a}}\end{array}$ & $\begin{array}{l}1.63 \\
(79)\end{array}$ & $\begin{array}{c}2.3 \\
(100)\end{array}$ & $\begin{array}{l}2.5 \\
(74)\end{array}$ & $\begin{array}{r}\text { From studies with detailed group composition in specific } \\
\text { habitat type (= no. of infants per year/total no. of males) }\end{array}$ & $1,2,3,7,12,16$ \\
\hline Initial population size & 3000 & 1400 & 600 & Stable age distribution & 9,14 \\
\hline $\begin{array}{l}\text { Carrying capacity }(K) \\
\text { (SD in } K \text { due to EV) }\end{array}$ & $\begin{array}{l}3000 \\
(300)\end{array}$ & $\begin{array}{l}1400 \\
(140)\end{array}$ & $\begin{array}{l}660 \\
(66)\end{array}$ & $\begin{array}{l}\text { When hunting is present, population is assumed to be } \\
\text { below } K \text {, but at } K \text { with no hunting }\end{array}$ & - \\
\hline Change in $K^{\mathrm{a}}$ & -1.7 & -4.0 & -2.24 & $\begin{array}{l}\text { Change in habitat cover between } 2002 \text { and 2005; no } \\
\text { difference in rates between protected and unprotected } \\
\text { forests }\end{array}$ & 8,10 \\
\hline Future change in $K(\mathrm{yr})$ & 50 & 50 & 50 & Occurs for entire length of scenario & - \\
\hline Population harvest & No & No & Yes & Considered significant in DSNP only & 10,13 \\
\hline $\begin{array}{l}\text { First and last year of } \\
\text { harvest }\end{array}$ & na & na & $0-50$ & $\begin{array}{l}\text { Harvesting assumed to occur for the entire } \\
\text { modeling period }\end{array}$ & 13 \\
\hline Harvest intervals & na & na & 1 & $\begin{array}{l}\text { Village groups tend to hunt once a month, ca. } 60 \% \\
\text { success rate }\end{array}$ & 13 \\
\hline $\begin{array}{l}\text { Females/males } \\
\text { harvested, age } 1-4 \mathrm{yr}^{\mathrm{a}}\end{array}$ & na & na & $2 / 3$ & $\begin{array}{l}\text { Iban people hunt adult males only, Mayan Dayaks } \\
\text { target all ages and sexes }\end{array}$ & 13 \\
\hline $\begin{array}{l}\text { Females/males/ } \\
\text { harvested, adult }^{\mathrm{a}}\end{array}$ & na & na & $1 / 1$ & & 13 \\
\hline${ }^{\mathrm{a}}$ Tested for & & & & & \\
\hline
\end{tabular}

percent of females breeding, mate monopolization, mortality rates for males and females, and severity and reproductive success in years of known catastrophes (the latter tested with the DSNP population).

We assumed the change in carrying capacity to be the change in habitat type of each of our study sites, based on calculations by Langner et al. (2007), and tested a range of $\pm 20 \%$ around the baseline value (Table 3a). Harvesting (hunting) was tested by increasing the hunting rates for both sexes and age categories by 5, 10 and 20 individuals, but this was only done for DSNP as hunting does not occur significantly at either of the other sites (Boonratana 1993, B. Goossens, V. Nijman \& S. Lhota unpubl. data) (Table $3 \mathrm{~b}$ ). The percentage of inbreeding due to recessive lethal alleles and the maximum age of reproduction were tested by decreasing the baseline value up to $50 \%$. We tested the age of first reproduction using the estimated range of maturity for proboscis monkeys (ages 3 to $5 \mathrm{yr}$ for females and 5 to $7 \mathrm{yr}$ for males) (Manansang et al. 2005, Yeager \& Boonratana in press) (Table 3c). The baseline values for the mean final population size after $50 \mathrm{yr}$ were used to compare the influence the parameters had on the population. If a population changed by $>100$ individuals by the end of the $50 \mathrm{yr}$ scenario, we considered the tested parameter to have a strong influence on the population.

\section{Management strategies}

We ran management scenarios to determine their influence on the declining population trends. We evaluated the following conservation strategies: (1) eliminating hunting, (2) eliminating fires, (3) eliminating deforestation, (4) reducing deforestation, (5) implementing reforestation programs, and (6) reconnecting sub-populations. Eliminating deforestation 
Table 3. Sensitivity testing parameters, using Lower Kinabatangan Wildlife Sanctuary (LKWS) as a baseline, except for 'Catastrophe severity' in (a) and 'Harvest' in (b) where Danau Sentarum National Park (DSNP) was used. Mort: mortality; EV: environmental variance; SD (given in parentheses): standard deviation; $K$ : carrying capacity; -: not possible to test with VORTEX

\begin{tabular}{|c|c|c|c|c|c|}
\hline (a) Scenarios $( \pm 20 \%)$ & Baseline & $-20 \%$ & $-10 \%$ & $+10 \%$ & $+20 \%$ \\
\hline Inbreeding: lethal equivalents & 3.14 & 2.51 & 2.83 & 3.45 & 3.77 \\
\hline Sex ratio at birth ( $\%$ males $)$ & 41.67 & 33.34 & 37.50 & 45.84 & 50.00 \\
\hline \multicolumn{6}{|l|}{ Females breeeding \% } \\
\hline $\mathrm{EV}$ & 7.00 & 5.60 & 6.30 & 7.70 & 8.40 \\
\hline LKWS & 45.75 & 36.60 & 41.18 & 50.33 & 54.90 \\
\hline Balikpapan Bay & 58.57 & 46.86 & 52.71 & 64.43 & 70.28 \\
\hline DSNP & 64.06 & 51.25 & 57.65 & 70.47 & 76.87 \\
\hline Mate monopolization ( $\%$ of breeding males) & 79.00 & 63.20 & 71.10 & 86.90 & 94.80 \\
\hline Female/male mortality, age $0-1$ yr (\%) (SD) & $40.00(8)$ & $32.00(6.40)$ & $36.00(7.20)$ & $44.00(8.80)$ & $48.00(9.60)$ \\
\hline Female/male mortality, age 1-2 yr (\%) (SD) & $10.00(2)$ & $8.00(1.60)$ & $9.00(1.80)$ & $11.00(2.20)$ & $12.00(2.40)$ \\
\hline Female/male mortality, age 2 yr-adult (\%) (SD) & $5.00(1)$ & $4.00(0.80)$ & $4.50(0.90)$ & $5.50(1.10)$ & $6.00(1.20)$ \\
\hline Female/male mortality, adult & & -10.9 & $(2)($ Age $)]+[(($ & 4)(Age 2)] & \\
\hline SD (Adult) & 3.50 & 2.80 & 3.15 & 3.85 & 4.20 \\
\hline \multicolumn{6}{|l|}{ Catastrophe severity (proportion) } \\
\hline Reproduction & 0.50 & 0.40 & 0.45 & 0.55 & 0.60 \\
\hline Survival & 0.77 & 0.62 & 0.69 & 0.85 & 0.92 \\
\hline \multicolumn{6}{|l|}{ Change in $K(\%$ per yr) } \\
\hline LKWS & -1.7 & -1.36 & -1.53 & -1.87 & -2.04 \\
\hline Balikpapan Bay & -4.0 & -3.2 & -3.6 & -4.4 & -4.8 \\
\hline DSNP & -2.24 & -1.79 & -2.02 & -2.46 & -2.69 \\
\hline (b) Scenarios: harvest (ind. $\mathrm{yr}^{-1}$ ) & Baseline & +5 & +10 & +20 & \\
\hline Female pre-adult & 2 & 7 & 12 & 22 & \\
\hline Female adult & 1 & 6 & 11 & 21 & \\
\hline Male pre-adult & 3 & 8 & 13 & 23 & \\
\hline Male post-adult & 1 & 6 & 11 & 21 & \\
\hline (c) Scenarios (-15 to $-50 \%)$ & Baseline & $-15 \%$ & $-25 \%$ & $-50 \%$ & \\
\hline Inbreeding: recessive lethals & 100 & 85 & 75 & 50 & \\
\hline Maximum age of reproduction (yr) & 25 & 21 & 19 & 13 & \\
\hline Age at first reproduction - Female/male ${ }^{\mathrm{a}}(\mathrm{yr})$ & $5 / 7$ & $4 / 6$ & $3 / 5$ & - & \\
\hline${ }^{a}$ Estimated age range of maturity & & & & & \\
\hline
\end{tabular}

was not considered a realistic scenario in Balikpapan Bay and DSNP; therefore, we modeled a reduction in deforestation rates to the next lowest level from the calculated values by Langner et al. (2007) to simulate a reduction in illegal logging. All other parameters were left unchanged. Numbers of surviving individuals and the extinction probabilities of each sub-population and of the entire population were compared to the baseline results. Scenarios were run 1000 times representing a $50 \mathrm{yr}$ period.

\section{RESULTS}

\section{Baseline scenarios}

The populations at each of our study sites experienced a decline (Fig. 2). Table 4 shows a summary of the 3 population simulation models over $50 \mathrm{yr}$.

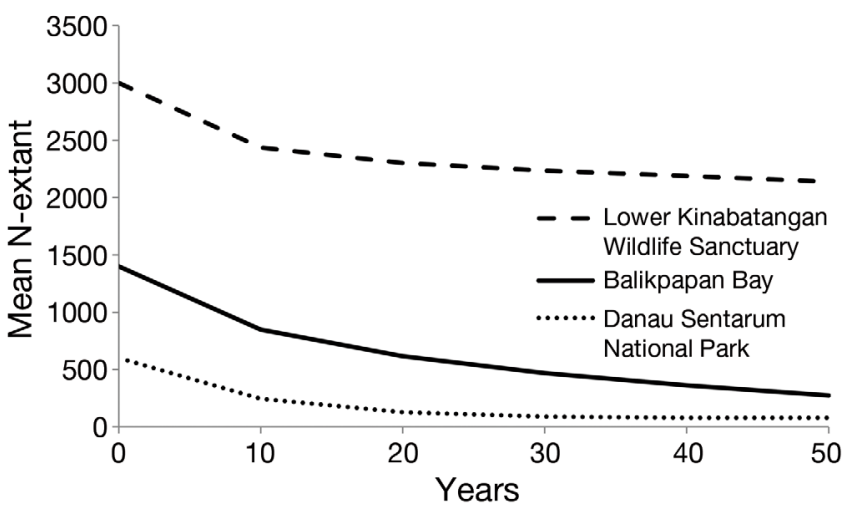

Fig. 2. Nasalis larvatus. Baseline scenario run for 2000 iterations representing 50 yr showing the mean number of extant individuals (N-extant) for populations at the 3 study sites

In the LKWS, the baseline model shows that none of the sub-populations of proboscis monkeys Nasalis larvatus are predicted to become extinct over the 
Table 4. Results from baseline scenarios (2000 iterations) for the Lower Kinabatangan Wildlife Sanctuary (LKWS), Balikpapan Bay (BB) and Danau Sentarum National Park (DSNP). Initial N: initial population size; PE: probability of population extinction; TE: mean number of years to extinction; det-r: deterministic growth rate (mean growth rate from average birth and death rates); stoc-r: mean growth rate (mean stochastic population growth/decline rate); $\mathrm{N}$-extant: mean number of individuals not extinct after $50 \mathrm{yr}$; SD: standard deviation; na: not applicable

\begin{tabular}{|lclclrr|}
\hline Site & Initial N & PE & TE & Det-r & Stoc-r (SD) & N-extant (SD) \\
\hline LKWS & 3000 & 0.00 & na & 0.07 & $0.002(0.05)$ & $2138(346.00)$ \\
BB & 1400 & 0.001 & 44.0 & 0.033 & $-0.036(0.14)$ & $273.67(232.63)$ \\
DSNP & 600 & 0.89 & 32.4 & 0.041 & $-0.13(0.19)$ & $81.06(79.45)$ \\
\hline
\end{tabular}

size, indicating this sub-population is highly unstable $(\mathrm{N}$-extant $=$ 81, $\mathrm{SD}=79.5)$.

\section{Sensitivity testing}

Of the non-manageable parameters tested for sensitivity, the majority did not have an influence on the mean final population size. The parameters that had the greatest influence on the mean

50 yr period (Fig. 3). The greatest drop in all 3 subpopulations occurs in the first $10 \mathrm{yr}$, and then stays fairly stable for the remaining $40 \mathrm{yr}$. The sub-populations change from 150, 1800 and 1050 individuals to 90, 1300 and 750, respectively, for a final population size after 50 yr of 2140 .

The proboscis monkeys in Balikpapan Bay are predicted to experience a rapid decline that does not stabilize by the end of the 50 yr scenario. Nevertheless, it shows a small probability of extinction ( $\mathrm{PE}=0.001$ ) in a mean time of $44 \mathrm{yr}$. The population in Balikpapan Bay is highly unstable, fluctuating greatly between iterations, dropping from 1400 individuals to a mean final population size of $274(\mathrm{SD}=233)$.

The population in DSNP has a predicted extinction risk of almost $90 \%$ in just over $30 \mathrm{yr}$ (Fig. 4). All but the largest sub-population have a $100 \%$ extinction risk, occurring in 5 to $15 \mathrm{yr}$. The largest sub-population has a $90 \%$ risk of extinction in $30 \mathrm{yr}$, with a mean final size of 30 individuals. Similar to the population in Balikpapan Bay, the standard deviation for this sub-population is similar to the mean final population final population size were infant female mortality, sex ratio at birth and proportion of breeding females; however, their effect was only evident when testing the extremes of the baseline values $( \pm 20 \%)$ and when the maximum age of reproduction was reduced from 25 to $13 \mathrm{yr}$.

Increasing the number of adult males or adult females hunted had the largest impact in the DSNP population, resulting in $100 \%$ extinction in all cases except when the number of non-adult males hunted was increased by 5 individuals ( $\mathrm{PE}=95 \%$ ). Hunting females increases the mean time to extinction from 32 to between 10.5 and 22.5 yr. Hunting males follows a similar pattern, the mean time to extinction increasing from 32 to between 14 and $24.5 \mathrm{yr}$. The mean time to extinction is more rapid when adult females and adult males are hunted as opposed to non-adults.

Varying the carrying capacity within $\pm 20 \%$ of the baseline values did not generally influence the final population sizes. In the LKWS, the mean population size changed from the baseline value of 2138 individuals to $2156(+20 \%)$ and to $2214(-20 \%)$. The varia-

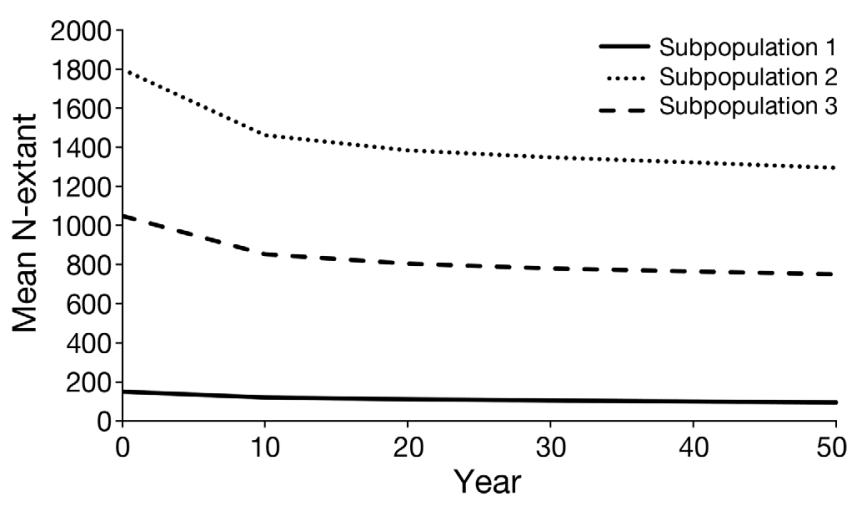

Fig. 3. Nasalis larvatus. Baseline scenario run for 2000 iterations representing 50 yr showing the mean number of extant individuals (N-extant) for the sub-populations in the Lower Kinabatangan Wildlife Sanctuary

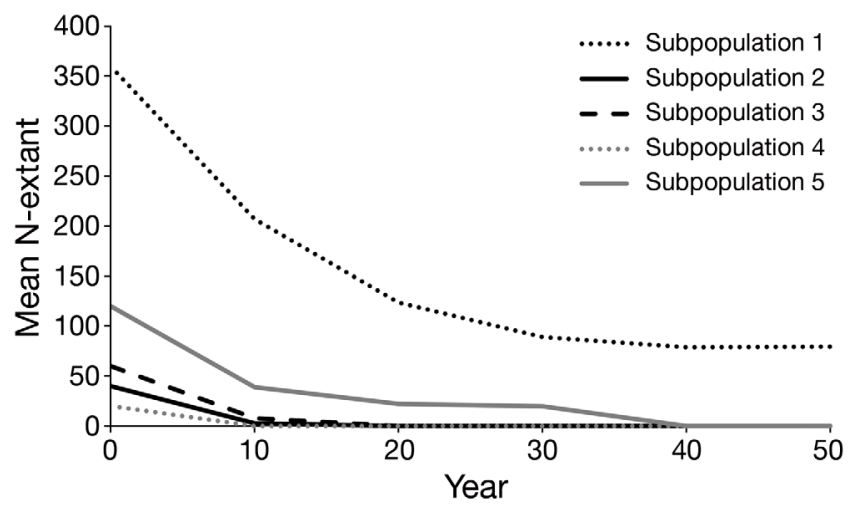

Fig. 4. Nasalis larvatus. Baseline scenario run for 2000 iterations representing $50 \mathrm{yr}$ showing the mean number of extant individuals (N-extant) for the sub-populations in Danau Sentarum National Park 
tions in the Balikpapan Bay and DSNP populations were smaller, changing from 274 individuals in Balikpapan Bay to a mean size of $285(+20 \%)$ and to 270 $(-20 \%)$, and from 80 to $77(+20 \%)$ and to $98(-20 \%)$ individuals in DSNP. All population trends followed a similar pattern to their baseline counterpart.

\section{Management scenarios}

We tested management strategies by changing 1 or 2 variables simultaneously to determine which para-

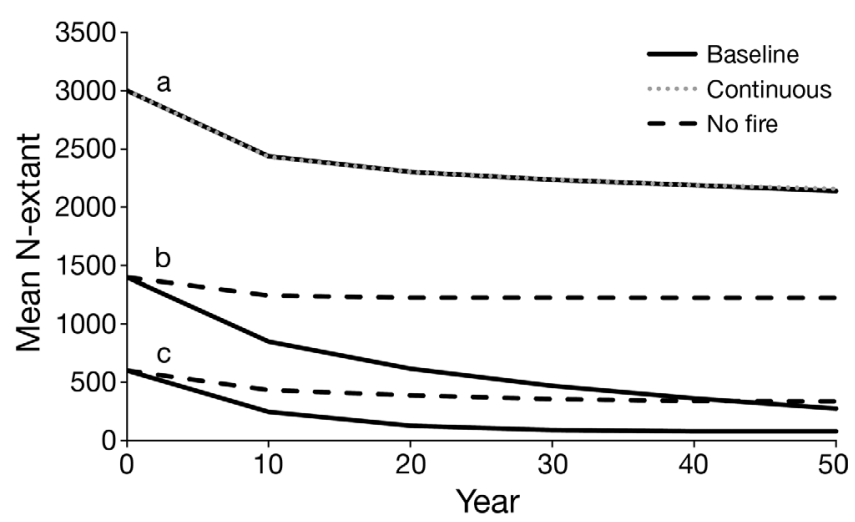

Fig. 5. Nasalis larvatus. Management scenarios with the greatest improvement on population trend and final size for: (a) Lower Kinabatangan Wildlife Sanctuary (note that the baseline and continuous lines are fully overlapping), (b) Balikpapan Bay and (c) Danau Sentarum National Park (DSNP). Baseline values are shown for comparison. Deforestation in Balikpapan Bay was reduced from 4.0 to $2.2 \% \mathrm{yr}^{-1}$, and DSNP, from 2.2 to $1.7 \% \mathrm{yr}^{-1}$ meters were important to slow population decline. Scenarios with the greatest effect were (1) reconnecting the population through corridors in the LKWS, and (2) eliminating fires in both Balikpapan Bay and DSNP (Fig. 5, Table 5).

As there was no risk of extinction in the LKWS, we ran scenarios to slow population decline or promote growth. All scenarios run for the LKWS (eliminating deforestation, reforestation and connecting the subpopulations through corridors) had little effect on the population trend and final population size, with final population size increasing by no more than 20 individuals. Increasing carrying capacity (i.e. reforestation) by $0.5 \%$ to reconnect the 3 sub-populations resulted in a final population size of 2158 individuals.

As our simulation suggested that the Balikpapan Bay population will decline, we tested strategies to slow this decline and to stabilize the population. Reducing the deforestation rate from 4.0 to $2.2 \%$ or to $1.7 \%$ a year did not influence the final size and followed the same trend as the baseline scenario. In contrast, eliminating fires led to a drastic change in the population, stabilizing at around 1225 individuals after an initial drop in the first $10 \mathrm{yr}$.

In DSNP, as 4 of the 5 sub-populations were predicted to become extinct, we investigated scenarios thought to ameliorate this risk and improve the overall population size. Eliminating hunting resulted in an overall final population size of 154 individuals and had the desirable effect of promoting sub-population persistence, although 3 of the sub-populations had a mean final population size of

Table 5. Results from baseline (2000 iterations) and management scenarios (1000 iterations) for the Lower Kinabatangan Wildlife Sanctuary (LKWS), Balikpapan Bay and Danau Sentarum National Park (DSNP). PE: probability of population extinction; TE: mean number of years to extinction; det-r: deterministic growth rate (mean growth rate from average birth and death rates); stoc-r: mean growth rate (mean stochastic population growth/decline rate); N-extant: mean number of individuals which are not extinct after $50 \mathrm{yr}$; SD: standard deviation

\begin{tabular}{|c|c|c|c|c|c|c|c|}
\hline Management scenario & $\mathrm{PE}$ & $\mathrm{TE}$ & Det-r & Stoc-r & $\mathrm{SD}$ (Stoc-r) & N-extant & SD (N-extant) \\
\hline \multicolumn{8}{|l|}{ LKWS } \\
\hline Baseline & 0 & 0 & 0.069 & 0.02 & 0.053 & 2138 & 346 \\
\hline No deforestation & 0 & 0 & 0.069 & 0.003 & 0.053 & 2144 & 326.03 \\
\hline Reconnect through corridors & 0 & 0 & 0.069 & 0.002 & 0.054 & 2158 & 351.51 \\
\hline Reforestation $(+1.0 \%)$ & 0 & 0 & 0.069 & 0.003 & 0.053 & 2150 & 339.19 \\
\hline \multicolumn{8}{|l|}{ Balikpapan Bay } \\
\hline Baseline & 0.001 & 44 & 0.033 & -0.036 & 0.143 & 274 & 232.63 \\
\hline No fires & 0 & 0 & 0.089 & 0.029 & 0.054 & 1225 & 88.03 \\
\hline Reduce deforestation $(-2.24 \%)$ & 0.002 & 46.5 & 0.033 & -0.036 & 0.144 & 276 & 242.94 \\
\hline \multicolumn{8}{|l|}{ DSNP } \\
\hline Baseline & 0.89 & 32.4 & 0.041 & -0.13 & 0.19 & 81 & 79.45 \\
\hline No hunting & 0.012 & 45.5 & 0.041 & -0.031 & 0.15 & 150 & 121.1 \\
\hline No fire & 0 & 0 & 0.097 & 0.009 & 0.059 & 334 & 36.18 \\
\hline Reduce deforestation $(-1.7 \%)$ & 0.87 & 32.3 & 0.041 & -0.13 & 0.2 & 63 & 63.06 \\
\hline
\end{tabular}


$<20$. Reducing deforestation to $1.70 \% \mathrm{yr}^{-1}$ followed the same population trend as the baseline population, with a mean final population size of 70 . The scenario with the greatest positive effect on overall population size was, however, eliminating fires, although 3 of the sub-populations still had a $100 \%$ extinction risk in 5 to $10 \mathrm{yr}$. The second largest subpopulation had a mean final size of 26 individuals and a $95 \%$ extinction risk. The largest of the subpopulations had a mean final population size of 333 individuals and $0 \%$ risk of extinction.

\section{DISCUSSION}

All 3 proboscis monkey Nasalis larvatus populations included in our study experience a simulated decline in size within the next $50 \mathrm{yr}$, with varied severity. Although the Balikpapan Bay population has almost no risk of extinction according to the $50 \mathrm{yr}$ scenario, the population is predicted to be a fifth of its original size and still declining, indicating that it is unstable and heading towards extinction. By implementing various management strategies, particularly for Balikpapan Bay and DSNP, the declining population trends can be slowed and perhaps even reversed. Generally, our analysis shows that implementing these strategies can increase the time to extinction, allowing management plans to be reevaluated and new strategies developed. Stochastic events have a greater effect on small populations, putting them at greater risk of extinction. The sensitivity of small populations or sub-populations makes it crucial for management strategies to be developed.

\section{Sensitivity testing}

Due to the shortage of long-term studies and the difficulties in maintaining populations in captivity, many of the life-history parameters we used in our proboscis monkeys PVA were based on small sample sizes or best estimates, or were derived from other primates with similar life histories or social structure. However, varying these parameter estimates within $20 \%$ of their baseline values did not appear to influence the trends or final sizes of the populations. Parameters such as maximum age of reproduction, proportion of breeding females, sex ratio at birth and infant female mortality only had a notable effect when using the extremes of the parameter estimate distribution. Hence, we consider our model robust with respect to proboscis monkeys' life-history para- meters. The most data-deficient parameters (mortality rates, severity of fire on reproduction and survival, and harvesting [hunting] rates) produced the greatest variation in population growth. These parameters are difficult to obtain, but, as they produce the greatest variation, they are potentially the most important in estimating population growth and, therefore, need to be the focus of future proboscis monkey studies.

\section{Corridors reconnecting populations}

All of the management scenarios tested for the LKWS produced similar results, although reconnecting the sub-populations through reforestation resulted in a slightly larger final population size. This may be due to the already large and stable population of proboscis monkeys in the LKWS; however, the absence of hunting and fires most likely played a major role. The deforestation rate in the LKWS is low, and, because of their high population size, the LKWS sub-populations are not as susceptible as those at other sites to dramatic population fluctuations due to stochastic events.

\section{Hunting}

Even though eliminating hunting in DSNP safeguarded the highest number of sub-populations from extinction, the sizes of these sub-populations declined dramatically, and the 4 smallest had mean final sizes ranging from 7 to 35 individuals. With sub-population sizes lower than the average group size of proboscis monkeys, these sub-populations could be considered unviable and effectively extinct. Also, as the values used for hunting are based on a small sample size (Robins 2008), this is presumably an underestimate of the importance of survival. As proboscis monkeys are legally protected, collecting hunting information has proved to be difficult, and villagers are reluctant to divulge their hunting habits (Meijaard \& Nijman 2003, J. G. Robins pers. obs.). The hunting pressure on proboscis monkeys in DSNP and the LKWS may be mitigated by the large Islamic populations that have laws prohibiting them from eating primates (Meijaard \& Nijman 2000, Lackman-Ancrenaz et al. 2001). However, the influx of human immigrants might increase the pressure on proboscis monkeys and may become a greater threat than is currently recognized. Upon future investigation into hunting in Kalimantan, this may be shown to be one of the reasons why proboscis monkeys are absent along the main rivers in the inte- 
rior of Borneo. In DSNP, the river is the main mode of transportation for logging. The logging companies travel through the area, disrupting local communities by damaging the riverine forest and introducing and illegally using firearms (Giesen \& Aglionby 2000). Hunting proboscis monkeys has become easier with the introduction of these illegal firearms, so proboscis monkeys are avoiding areas of significantly higher river traffic and fishing activities, thereby restricting themselves to patches smaller than the area naturally available to them (Robins 2008).

Hunting is currently considered negligible in Balikpapan Bay. However, the creation of the Pulau Balang Bridge could change this. The proposed road and bridge would separate the Sungai Wain Protection Forest and mangrove forest from each other, opening up the area to more people and presumably increasing the incidence of poaching. As timber extraction from the mangrove forest is not sufficiently enforced and illegal logging is already rife, improving access to the forest through road development will likely drive an increase in hunting. This already unstable population could easily become extinct if this occurs. Perhaps the best way to protect the proboscis monkeys of Balikpapan Bay would be to halt any industrial development outside the area allocated for industry and, above all, to prevent further encroachment by halting plans for the proposed Pulau Balang Bridge and connecting road in favor of an alternative transportation route, which would avoid the fragile Balikpapan Bay coast.

\section{Fires}

Fire is the greatest threat to the survival of proboscis monkeys in Balikpapan Bay and DSNP. Whereas the baseline scenario for Balikpapan Bay shows a continuous decrease in the population, resulting in a population one-fifth of its original size, eliminating forest fires allows the population to stabilize after $10 \mathrm{yr}$, falling by only 200 individuals. Although the mangrove forest is not directly affected by fires, proboscis monkeys in Balikpapan Bay appear to be dependent on food resources from the non-mangrove fringing on the inner edge of the mangrove belt (S. Lhota unpubl. data). In addition to forest fires, this forest is shrinking due to a combination of oil palm plantations, industrial and urban development and illegal logging. In DSNP, not all the sub-populations could be rescued by eliminating fires, but those that persist would have an increased mean time to extinction of 10 to $15 \mathrm{yr}$. The overall population size also drops to half its initial size, as opposed to the baseline scenario of $<100$ individuals.

Fire is used to clear land and convert forests to plantations throughout Borneo. Forests which have previously been burned become more susceptible to future fire damage (Cochrane et al. 1999, Siegert et al. 2001). Due to the rate of deforestation in Borneo, the effects of El Niño have been altered, resulting in more severe droughts. The combination of logging, droughts and fires has negatively impacted forested areas. By converting burned forests to other land uses instead of allowing them to recover, the effects of fire are continuously increasing (Dennis \& Colfer 2006). Currently, there are no data available on the effect the fires have on the survival and reproduction of proboscis monkeys, even though they live in the highest fire risk habitat in Borneo (Siegert et al. 2001).

\section{Conservation implications}

The population trends emerging from this PVA suggest that if the current situation remains unchanged, proboscis monkey populations throughout Borneo may experience a similar pattern of population decline by becoming highly fragmented and unstable; this applies particularly to those which do not receive as much attention from researchers and officials. As populations respond differently to the various management scenarios, it is important for strategies to be developed based on the characteristics of individual populations and their habitat, targeting the factors with the most influence on the survival and trends of the population. As management strategies are implemented, further PVA models must also be employed, to continually reassess the status of the strategies.

Habitat protection is the major requirement for the survival of proboscis monkeys in all 3 areas modeled, although hunting may play a larger role in certain areas than currently recognized. Protection must not be merely on paper, as the survival of proboscis monkey populations depends on the joint efforts of the government, local communities and conservation organizations to actively ensure and enforce protection of their habitat. Interviews in Balikpapan Bay showed that hunters and loggers feared patrolling enforcement, even though patrols were quite rare, and the interviews alone were enough to temporarily halt illegal activities (S. Lhota unpubl. data). The presence of patrols in Balikpapan Bay and DSNP could have an immediate impact on the illegal extraction from the forest, of both wildlife and trees. 
LKWS, Balikpapan Bay and DSNP are important habitats in Borneo, with high biodiversity and large numbers of endemic species. These areas are popular tourist destinations, which, if managed well, can bring benefits and provide incentives for governments and communities to maintain their status and beauty. Conservation can give communities a chance to be involved. There has been a strong conservation presence in the LKWS in the past decade, with a number of local and international non-governmental organizations and research stations organizing and implementing eco-tourism projects focusing on reforestation that can ultimately improve the connectivity of forest fragments and prevent the further expansion of oil palm plantations. Already, these schemes appear to be having a positive influence on proboscis monkey populations, which seem to be becoming more stable with time. These areas are important for education, training and research, providing excellent opportunities to observe the interaction between wildlife and their habitat and appreciate the important role wildlife plays in the productivity of the forest. This protection cannot be achieved without collaboration from the local, state and provincial governments, local communities and conservation organizations. By working together these groups can help to raise awareness, and to educate and train children and villagers to play an active role in the conservation of their forest.

Acknowledgements. The fieldwork by D.J.S. and J.G.R. was funded by by the Zoological/Veterinary Studentship by the North of England Zoological Society and the Conservation Grant by the International Primatological Society. Fieldwork by S.L. in Balikpapan Bay was supported by Grant No. MSMT 6007665801 from the Ministry of Education, Youth and Sports of the Czech Republic, a research grant from Primate Conservation Inc., and a conservation grant from the Primate Society of Great Britain. We thank Cassie Huntley and Clare Wilcockson and all the staff at Danau Girang Field Centre for field assistance for the Kinabatangan survey, Robert Lacy for his advice on VORTEX, and Stephen Gregory, Luigi Boitani and 3 anonymous referees for their constructive comments on the manuscript. We thank Laurentius Ambu, Director of the Sabah Wildlife Department, for granting us permission to carry out proboscis monkey surveys in the Lower Kinabatangan Wildlife Sanctuary. J.G.R. thanks all at Riak Bumi for providing logisitical support during his fieldwork in DSNP.

\section{LITERATURE CITED}

Ancrenaz M, Gimenez O, Ambu L, Ancrenaz K and others (2005) Aerial surveys give new estimates for orang-utans in Sabah, Malaysia. PLoS Biol 3:e3

Ballou J, Lacy R, Miller P (2003) Simulation modelling and population viability analysis. Available at: www.tapirs.org/
Downloads/vortex/Simulation-Modeling+Population-Viability-Analysis.doc (accessed on 26 November 2008)

- Bennett EL, Sebastian AC (1988) Social organization and ecology of proboscis monkeys (Nasalis larvatus) in mixed coastal forest in Sarawak. Int J Primatol 9:233-256

Boonratana R (1993) The ecology and behaviour of the proboscis monkey (Nasalis larvatus) in the lower Kinabatangan, Sabah. PhD thesis, Mahidol University, Bangkok

> Boonratana R (2000) Ranging behavior of proboscis monkeys (Nasalis larvatus) in the lower Kinabatangan, northern Borneo. Int J Primatol 21:497-518

> Cochrane MA, Alencar A, Schulze MD, Souza CM Jr, Nepstad DC, Lefebvre P, Davidson EA (1999) Positive feedbacks in the fire dynamic of closed canopy tropical forests. Science 284:1832-1835

Curran LM, Trigg SN, McDonald AK, Astiani D and others (2004) Lowland forest loss in protected areas of Indonesian Borneo. Science 303:1000-1003

Davison GWH (2006) Rehabilitation and restoration of habitat near the Kinabatangan Wildlife Sanctuary, Sabah Malaysia. Available at: www.iucn.org (accessed on 30 November 2008)

Dennis RA (1999) A review of fire projects in Indonesia 1982 - 1998. Center for International Forestry Research, Bogor

Dennis RA, Colfer CP (2006) Impacts of land use and fire on the loss and degradation of lowland forest in 1983-2000 in East Kutai District, East Kalimantan, Indonesia. Singap J Trop Geogr 27:30-48

Dennis RA, Erman A, Stolle F, Applegate G (2000) The underlying causes and impacts of fires in south-east Asia. Site 5. Danau Sentarum, West Kalimantan Province, Indonesia. Center for International Forest Research, Jakarta. Available at www.cifor.org/fire/pdf/pdf53.pdf

> Dennis RA, Mayer J, Applegate G, Chokkalingam U and others (2005) Fire, people and pixels: linking social science and remote sensing to understand underlying causes and impacts of fires in Indonesia. Hum Ecol 33: 465-504

Fredriksson GM, de Kam M (1999) Strategic plan for the conservation of the Sungai Wain Protection Forest. The International Ministry of Forestry and Estate CropsTropenbos Kalimantan Project, Wanariset Samboja

Giesen W, Aglionby J (2000) Introduction to Danau Sentarum National Park, West Kalimantan. Borneo Res Bull $31: 5-28$

> Goossens B, Chikhi L, Jalil MF, Ancrenaz M and others (2005) Patterns of genetic diversity and migration in increasingly fragmented and declining orang-utan (Pongo pygmaeus) populations from Sabah, Malaysia. Mol Ecol 14:441-456

Hamilton S, Moller H (1995) Can PVA models using computer packages offer useful conservation advice? Sooty shearwaters Puffinus griseus in New Zealand as a case study. Biol Conserv 72:107-117

Lackman-Ancrenaz I, Ancrenaz M, Saburi R (2001) The Kinabatangan Orangutan Conservation Project. In: Chicago Zoological Society (eds) Proceedings of a conference on the apes: challenges for the 21st century. Brookfield Zoo, Chicago, IL, p 262-265

Lacy RC, Borbat M, Pollak JP (2009) VORTEX: a stochastic simulation of the extinction process, Version 9.99. Chicago Zoological Society, Brookfield Zoo, Chicago, IL

Langner A, Miettinen J, Siegert F (2007) Land cover change 2002-2005 in Borneo and the role of fire derived from 
MODIS imagery. Glob Change Biol 13:2329-2340

Manansang J, Traylor-Holzer K, Reed D, Leus K (eds) (2005). Indonesian proboscis monkey population and habitat viability assessment: final report. IUCN/SSC Conservation Breeding Specialist Group, Apple Valley, MN. Available at: www.cbsg.org/cbsg/workshopreports/23/ proboscis_phva_final_report_a4p.pdf (accessed on 28 September 2008)

Matsuda I (2008) Feeding and ranging behaviors of proboscis monkey (Nasalis larvatus) in Sabah, Malaysia. PhD thesis, Hokkaido University, Hokkaido

Matsuda I, Tugga A, Higashi S (2009) Ranging behavior of proboscis monkeys in a riverine forest with special reference to ranging in inland forest. Int $\mathrm{J}$ Primatol 30: 313-325

Meijaard E, Nijman V (2000) Distribution and conservation of the proboscis monkey (Nasalis larvatus) in Kalimantan, Indonesia. Biol Conserv 92:15-24

Meijaard E, Nijman V (2003) Primate hotspots on Borneo: predictive value for general biodiversity and the effects of taxonomy. Conserv Biol 17:725-732

Meijaard E, Nijman V, Supriatna J (2008) Nasalis larvatus. IUCN Red List of Threatened Species, Version 2010.4. Available at: www.iucnredlist.org (accessed on 10 December 2010)

Miller PS, Lacy RC (2005) VORTEX: a stochastic simulation of the extinction process, Version 9.50. User's manual. Conservation Breeding Specialist Group (SSC/IUCN), Apple Valley, MN

Murai T (2004) Social behaviors of all-male proboscis monkeys when joined by females. Ecol Res 19:451-454

Ralls K, Ballou J, Templeton A (1988) Estimates of lethal equivalents and the cost of inbreeding in mammals. Conserv Biol 2:185-193

Robins JG (2008) Assessing the impact of anthropogenic activities on the distribution of proboscis monkeys (Nasalis larvatus) in Danau Sentarum National Park,

Editorial responsibility: Luigi Boitani,

Rome, Italy
West Kalimantan, Indonesia. MSc thesis, Oxford Brookes University, Oxford

Salter RE, MacKenzie NA (1985) Conservation status of the proboscis monkey in Sarawak. Biol Conserv 33:119-132

Sebastian AC (1994) A preliminary investigation of the proboscis monkey population in Danau Sentarum Wildlife Reserve, western Kalimantan, Indonesia. Asian Wetland Bureau, Bogor

Sebastian AC (2000) Proboscis monkeys in Danau Sentarum National Park. Borneo Res Bull 31:359-371

Sha J, Bernard H, Nathan S (2008) Status and conservation of proboscis monkeys (Nasalis larvatus) in Sabah, East Malaysia. Primate Conserv 23:107-120

Shaffer M, Watchman LH, Snape WJ III, Latchis IK (2002) Population viability analysis and conservation policy. In: Beissinger SR, McCullough DR (eds) Population viability analysis. University of Chicago Press, London, p 123-142

Siegert F, Ruecker G, Hinrichs A, Hoffmann AA (2001) Increased damage from fires in logged forests during droughts caused by El Niño. Nature 414:437-440

Wadley RL (2006) Wildlife diversity on the periphery of Danau Sentarum National Park, West Kalimantan, Indonesia. Borneo Res Bull 37:157-174

Yeager CP (1990) Proboscis monkey (Nasalis larvatus) social organization: group structure. Am J Primatol 20:95-106

Yeager CP (1991) Proboscis monkey (Nasalis larvatus) social organization: intergroup patterns of association. Am J Primatol 23:73-86

Yeager CP, Blondal TK (1992) Conservation status of the proboscis monkey ( $N$. larvatus) at Tanjung Putting National Park, Kalimantan Tengah, Indonesia. In: Ismail G, Mohamed M, Omar S (eds) Forest biology and conservation in Borneo. Yayasan Sabah Center for Borneo Studies Publication No. 2, Kota Kinabalu, p 220-228

Yeager CP, Boonratana C (in press) Proboscis monkey. In: Rowe N, Myers M (eds) All the world's primates. Pogonias Press, Charlestown, RI

Submitted: December 29, 2010; Accepted: September 23, 2011 Proofs received from author(s): December 19, 2011 